\title{
Predictors of anthracycline-induced cardiotoxicity in a retro-prolective cohort of children surviving cancer
}

\author{
Rodolfo Rivas-Ruiz, ${ }^{1}$ Kingston Ureña-Wong, ${ }^{2 *}$ Osvaldo Daniel Castelán-Martínez, ${ }^{3}$ \\ Yadira Betanzos-Cabrera, ${ }^{4}$ César Lazo-Cárdenas, ${ }^{4}$ César Ramírez-Portillo ${ }^{4}$ and Enrique López-Aguilar ${ }^{4}$ \\ ${ }^{1}$ Instituto Mexicano del Seguro Social, Center of Clinical Training and Research, Health Research Coordination; ${ }^{2}$ Asociación para Evitar la Ceguera \\ en México, I.A.P.; ${ }^{3}$ Universidad Nacional Autónoma de México, Facultad de Estudios Superiores Zaragoza, Clinical Pharmacology Laboratory; \\ 4Instituto Mexicano del Seguro Social, Centro Médico Nacional Siglo XXI, Hospital de Pediatría "Dr. Frenk Freund". Mexico City, Mexico
}

\begin{abstract}
Introduction: Cardiotoxicity is an adverse reaction associated with the use of anthracyclines. Objective: To estimate the factors associated with the development of anthracycline cardiotoxicity in pediatric patients surviving cancer. Method: Retro-prolective cohort of children diagnosed with cancer and treated with anthracyclines. Baseline echocardiographic determination of ejection fraction (LVEFO) was carried out before the start of treatment and again at 12 months (LVEF1). Demographic characteristics and treatment were obtained from the medical record. A multiple logistic regression (MLR) model was constructed; LVEF1 < $50 \%$ was the dependent variable, which was adjusted for the main confounding variables. Results: Sixty-five patients were included, out of which $36.9 \%$ were females and $56.8 \%$ had a solid tumor. LVEFO was $74.79 \pm 7.3 \%$ and LVEF1, $67.96 \pm 6.7 \%(p=0.001) ; 60 \%$ developed cardiotoxicity. In the MLR, only a cumulative dose $>430 \mathrm{mg}$ was associated with cardiotoxicity $(p=0.001)$. Conclusions: In Mexican children, an anthracycline cumulative dose $>430 \mathrm{mg}$ should be avoided in order to prevent cardiotoxicity.
\end{abstract}

KEY WORDS: Anthracyclines. Cardiotoxicity. Risk factors.

\section{Factores predictores de cardiotoxicidad inducida por antraciclinas en una cohorte retroprolectiva de niños supervivientes de cáncer}

\section{Resumen}

Introducción: La cardiotoxicidad es una reacción adversa asociada al uso de antraciclinas. Objetivo: Estimar los factores asociados al desarrollo de cardiotoxicidad por antraciclinas en pacientes pediátricos supervivientes de cáncer. Método: Cohorte retroprolectiva de niños con diagnóstico de cáncer tratados con antraciclinas. Se realizó determinación ecocardiográfica basal de la fracción de expulsión (FEVio) antes del inicio del tratamiento y a los 12 meses (FEVi1). Del expediente se obtuvieron las características demográficas y el tratamiento. Se realizó un modelo de regresión logística múltiple (RLM); la FEVi1 < 50 \% fue la variable dependiente, que se ajustó por las principales variables confusoras. Resultados: Se incluyeron 65 pacientes, 36.9 \% fue del sexo femenino y $56.8 \%$ presentó un tumor sólido. La FEViO fue de $74.79 \pm 7.3 \%$ y la FEVi1, de $67.96 \pm 6.7 \%$ ( $p=0.001) ; 60 \%$ desarrolló cardiotoxicidad. En la RLM solo la dosis acumulada > $430 \mathrm{mg}$ se asoció a cardiotoxicidad $(p=0.001)$. Conclusiones: En los niños mexicanos se debe evitar una dosis acumulada > $430 \mathrm{mg}$ de antraciclinas para evitar la cardiotoxicidad.

PALABRAS CLAVE: Antraciclinas. Cardiotoxicidad. Factores de riesgo. 


\section{Introduction}

The incidence of cancer in Mexico has been estimated at 126 cases/million/year. ${ }^{1,2}$ Reports made by the World Health Organization show that the incidence of cancer in children younger than 15 years has increased by more than $200 \%$ in developing countries, with a predominance of leukemias and lymphomas..$^{3-5}$ In addition to the increase in cancer global incidence, treatment improvements have allowed to increase survival, but treatment-associated adverse reactions have also grown. ${ }^{6}$ In the case of anthracyclines, ${ }^{7}$ adverse events have been reported both during therapy administration and in the long term.

Pediatric patients who survive cancer are eight times more likely to die from heart disease and 15 times more likely to suffer from heart failure than their siblings who did not have cancer. ${ }^{8,9}$ Cardiotoxicity (CTX) is the leading non-cancerous cause of serious complications, and the risk persists for up to 45 years after treatment conclusion, in addition to constituting the second leading cause of death, after secondary cancer. ${ }^{10}$

Anthracycline-treated childhood cancer survivors experience subclinical cardiac dysfunction for up to six years after treatment completion. ${ }^{1}$ Furthermore, CTX can develop in the long-term and occur at between four to 20 years after treatment conclusion. ${ }^{11}$ Some studies report that the prevalence of this complication is as high as $57 \% .^{12}$ In Mexico, the incidence of CTX in children surviving cancer is not known.

Acute CTX can cause from mild electrocardiographic changes to life-threatening arrhythmias. ${ }^{13}$ Long-term cardiotoxic effects have been described to depend on drug doses ${ }^{14}$ and to be clinically more important than the acute ones.

Although some factors associated with acute CTX have been described, few studies address the factors associated with the development of long-term CTX. The purpose of the present study was to assess the factors associated with the development of long-term CTX in anthracycline-treated children who survived cancer.

\section{Method}

Retro-prolective cohort study of cancer surviving patients attended to at the Oncology Department of the Pediatric Hospital "Dr. Silvestre Frenk Freund" between 2013 and 2018. Patients aged $<16$ years who were cancer survivors (disease-free period $\geq 5$ years), who received treatment with anthracyclines, who had no evidence of previously-existing heart disease, corroborated by echocardiography, were included. All participants had to have a baseline echocardiogram, obtained within the first month after starting anthracycline treatment at the Cardiology Department by attending physicians. Patients with clinical anemia, corroborated by blood count (hemoglobin $<7 \mathrm{mg} / \mathrm{dL}$ ) or with hemodynamic repercussion were excluded. Ejection fraction determination was performed before treatment (LVEF0) and 12 months after treatment initiation (LVEF1) at the Pediatric Cardiology Department of the hospital. Information on demographic characteristics and treatment was obtained from the medical record. CTX was defined as a $10 \%$ decrease in LVEF1 in relation to the baseline value, in accordance with the guidelines for cancer treatments and cardiovascular toxicity of the European Society of Cardiology. ${ }^{15}$

The sample size was calculated with the difference between proportions formula, assuming an alpha $=0.05$ and 1-beta $=0.20$. The Epi Info program was used. Eight percent of subjects with CTX prior to chemotherapy and $40 \%$ one year after treatment were estimated. The sample was defined with at least 60 patients, a size that ensured stability of the multiple logistic regression (MLR) models adjusted for six variables.

The following quantitative variables were summarized in the descriptive statistics: age, weight, height, LVEF0, LVEF1. Inferential methods were used to corroborate the type of distribution; if the variables did not show normal distribution with this procedure, Kolmogorov-Smirnoff normality tests were carried out. Variables with normal distribution were expressed as means and standard deviations, and freely distributed variables, as medians and 25-75 interquartile ranges (IQR). Nominal variables (gender, dichotomous age, tumor type) were recorded using frequencies and percentages.

To determine the risk factors, nominal variables were analyzed using Pearson's chi-square test. To assess clinical relevance, relative risks (RR) were calculated with $95 \%$ confidence interval $(\mathrm{Cl})$. Quantitative variables with normal distribution were analyzed with Student's t-test or Mann-Whitney's U-test. Variables that were statistically significant in the bivariate model were selected to be included in the MLR model, which was carried out by descending steps, in order to find the independent variables with the highest association. To assess the dose with the highest risk for 
CTX, a ROC curve was plotted in order to find the point with the highest positive likelihood ratio (PLR).

The SPSS program, version 25 , was used for statistical analysis. A p-value $<0.05$ was determined to be statistically significant in all cases.

This study was carried out following the ethical guidelines for research in human subjects ${ }^{16}$ set forth in the Declaration of Helsinki, the Nuremberg Code, the Belmont Report, the CIOMS Guidelines and the Good Clinical Practice Guidelines for the Americas, as well as in accordance with the Regulations of the General Statute of Health in Matters of Health Research, in particular with article 13 regarding the respect, dignity and protection of the rights of the pediatric patient; article 17, with regard to which the research was considered to be of minimum risk; and 20 and 21, which regulate informed consent and assent. The research was also limited to the indications of Mexican Official Standard NOM 012-SS3-2012 for the execution of research projects for health in human subjects. All patients who received anthracyclines and who were in the cohort of cancer survivors (equitable subject selection) were invited to participate. All parents of patients who agreed to participate in the protocol signed a consent letter after being informed about the purposes of the research. Children older than eight years signed informed assent letters.

As part of the follow-up protocol, all patients received dexrazoxane as a cardioprotective agent. Those in whom CTX was detected were referred to the Cardiology Department to receive an angiotensin converting enzyme inhibitor treatment and were followed-up (risk-benefit balance).

The study has social value because cancer survivors are currently not systematically evaluated in pediatric practice. The parents of all participants will be contacted to inform them on the results of the research.

The research was reviewed and accepted by the National Commission for Scientific Research of the Mexican Institute of Social Security with number R-2013-785-040.

\section{Results}

Sixty-five patients who met the inclusion criteria were recruited. Baseline characteristics of the population are summarized in Table 1. Among the participants, $36.9 \%$ were females. As for age, $60 \%$ of participants were older than five years at diagnosis. Solid neoplasms accounted for $56.8 \%$ of tumors.
Table 1. Baseline characteristics of 65 children surviving cancer

\begin{tabular}{|c|c|c|}
\hline Variable & $\mathrm{n}$ & $\%$ \\
\hline $\begin{array}{l}\text { Gender } \\
\text { Female }\end{array}$ & 24 & 36.9 \\
\hline $\begin{array}{l}\text { Age at diagnosis } \\
\leq 5 \text { years } \\
>5 \text { years }\end{array}$ & $\begin{array}{l}26 \\
39\end{array}$ & $\begin{array}{l}40.0 \\
52.3\end{array}$ \\
\hline $\begin{array}{l}\text { Type of tumor } \\
\text { Hematolymphoid } \\
\text { Solid }\end{array}$ & $\begin{array}{l}26 \\
39\end{array}$ & $\begin{array}{l}40.0 \\
60.0\end{array}$ \\
\hline Baseline weight in $\mathrm{kg}(\mathrm{IQR})$ & \multicolumn{2}{|c|}{$15.5(11.5-24.7)$} \\
\hline Cumulative dose in $\mathrm{mg}(\mathrm{IQR})^{\star}$ & \multicolumn{2}{|c|}{$320(165-485)^{*}$} \\
\hline Baseline height in $\mathrm{cm}$ & \multicolumn{2}{|c|}{$107 \pm 27$} \\
\hline LVEFO \% (mean) & \multicolumn{2}{|c|}{$74.79 \pm 7.3$} \\
\hline LVEF \% (mean) & \multicolumn{2}{|c|}{$67.96 \pm 6.7$} \\
\hline
\end{tabular}

${ }^{*}$ Cumulative dose of all three anthracycline groups.

$I Q R=$ interquartile range, $L V E F O=$ left ventricular ejection fraction prior to chemotherapy, LVEF1 = left ventricular ejection fraction after chemotherapy.

Baseline weight of the participants was $15.5 \mathrm{~kg}$ (IQR = 11.5-24.7 kg), baseline height was $107 \pm 26.6$ $\mathrm{cm}$. Anthracycline cumulative dose (epirubicin, doxorubicin, or daunorubicin) had a median of $385 \mathrm{mg} / \mathrm{m}^{2}$ body surface area (IQR $=184-325)$. Participants' mean LVEF0 was $74.8 \pm 7.3 \%$.

Thirty-nine patients $(60 \%)$ developed early CTX. When the risk factors were analyzed, the male gender was found to have a RR $=2.09(95 \% \mathrm{Cl}=0.7-6.13)$ for the development of cardiotoxicity. Among the three types of anthracyclines used in the study, epirubicin had a RR $=2.35(95 \% \mathrm{Cl}=0.7-7.61)$. Hematolymphoid-type neoplasms had a RR $=1.75(95 \% \mathrm{Cl}=0.96-3.15)$. The rest of RRs are summarized in Table 2. RRs are represented in Figure 1.

Mean LVEF0 and LVEF1 were compared with Student's t-test, with a mean difference of $10 \%$ being found $(p=0.001)$, which can be observed in Figure 2.

The prevalence of CTX in our population was $60 \%$. The rest of anthracycline-associated complications were neutropenia and fever (18\%), mucositis $(6.2 \%)$, thrombocytopenia, and sepsis (3.1\%).

A logistic regression model was calculated, where the dependent variable was CTX, adjusted for age and cumulative dose, which were the main confounding variables (Table 3 ).

The stepwise descending logistic regression method was used in order for the main variables associated with the development of cardiotoxicity to remain within the model. In step 4 of the model, the epirubicin 


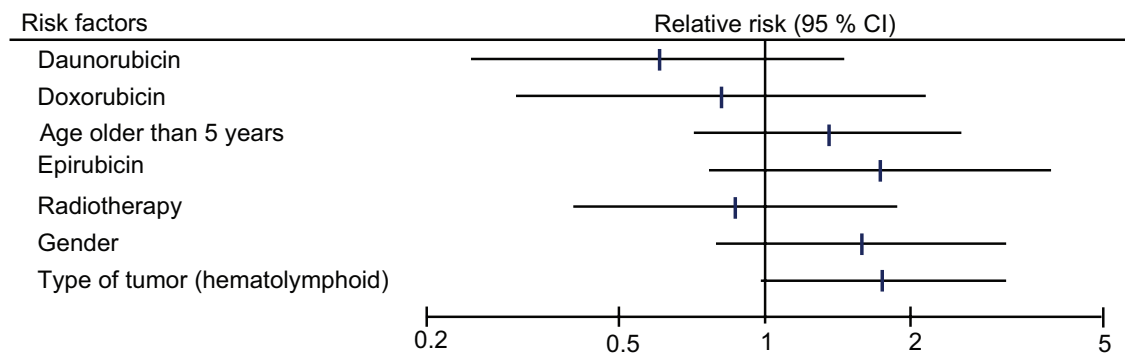

Figure 1. Main risk factors associated with the development of cardiotoxicity.

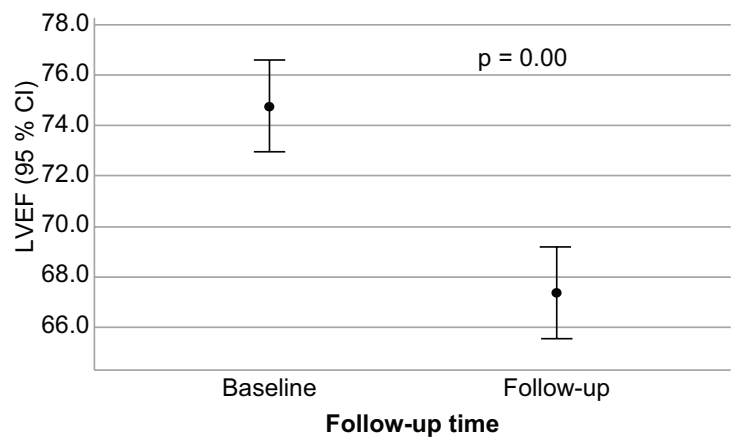

Figure 2. Comparison of ejection fraction means at baseline versus at 12 months. LVEF = left ventricular ejection fraction.

variable had an odds ratio $(\mathrm{OR})=4.69(95 \% \mathrm{Cl}=$ $0.75-29.03$ ), cumulative dose had an $\mathrm{OR}=1.004$ (95 $\% \mathrm{Cl}=1.001-1.007)$.

Since the cumulative dose was the only variable associated with CTX, a ROC curve was plotted (Fig. 3), where an area under the curve of 0.716 was found $(95 \% \mathrm{Cl}=0.55-0.882)$. The $260 \mathrm{mg}$ dose had a PLR of 1.84; the $380 \mathrm{mg}$ dose, of 2.15; and the 430 $\mathrm{mg}$ dose, of 3.51 (Fig. 4).

\section{Discussion}

Some risk factors associated with anthracycline CTX have been identified, which are potentially modifiable, such as cumulative dose, rate of administration, concomitant treatments, or physical activity. However, there are few studies with long-term follow-up where these possible risk factors are adjusted according to possible confounders. To the best of our knowledge, this is the first study in Mexico where risk factors for the development of CTX are assessed with multivariate models.

The present study focused on cancer surviving patients, i.e., those who developed CTX after treatment, which rules out patients who had acute toxicity, as we described in other investigations. ${ }^{17}$
Table 2. Risk factors associated with the development of cardiotoxicity

\begin{tabular}{|c|c|c|c|c|}
\hline \multirow[t]{2}{*}{ Variable } & \multicolumn{2}{|c|}{ Cardiotoxicity } & \multirow{2}{*}{$\begin{array}{c}\text { Relative } \\
\text { risk }\end{array}$} & \multirow[t]{2}{*}{$95 \% \mathrm{Cl}$} \\
\hline & $\begin{array}{c}\text { Yes } \\
(n=26)\end{array}$ & $\begin{array}{c}\text { No } \\
(n=39)\end{array}$ & & \\
\hline Males & 19 & 22 & 1.6 & $0.78-3.21$ \\
\hline Doxorubicin versus & 3 & 6 & \multicolumn{2}{|c|}{ Reference } \\
\hline Epirubicin & 21 & 25 & 1.4 & $0.51-3.63$ \\
\hline Daunorubicin & 4 & 11 & 0.81 & $0.22-2.78$ \\
\hline $\begin{array}{l}\text { Hematolymphoid } \\
\text { neoplasm }\end{array}$ & 15 & 12 & \multirow[t]{2}{*}{1.8} & \multirow[t]{2}{*}{$1.01-3.22$} \\
\hline Solid tumor & 12 & 27 & & \\
\hline Age $>5$ years & 16 & 18 & 1.4 & $0.72-2.57$ \\
\hline Radiotherapy & 5 & 9 & 0.9 & $0.39-1.88$ \\
\hline
\end{tabular}

$\mathrm{RR}=$ relative risk, $\mathrm{Cl}=$ confidence interval.

International reports indicate that the prevalence of CTX in patients receiving anthracyclines is approximately $40 \%$; however, in our analysis it was $60 \%$, which can be attributed to the fact that in our population the incidence of hematolymphoid neoplasms is higher than in other populations.

In the bivariate model, hematolymphoid neoplasms had a $R R=1.75$, which was not significant, probably due to an insufficient sample size, since an interval lower limit of 0.97 indicates a trend towards risk. A similar situation was observed with the male gender and epirubicin; these factors may be significant if the sample size is increased, as indicated in other studies. ${ }^{15}$

Although cardiac evaluation has evolved, ejection fraction reduction and symptomatic congestive heart failure (current CTX outcomes) ${ }^{18}$ generally occur weeks or years after treatment conclusion. ${ }^{19}$ Ejection fraction measurement continues to be used in clinical practice because it is readily accessible and highly 
Table 3. Logistic regression model for the development of cardiotoxicity associated with the use of anthracyclines

\begin{tabular}{|c|c|c|c|c|c|}
\hline \multirow[t]{2}{*}{ Variables } & & \multirow[t]{2}{*}{ B } & \multirow[t]{2}{*}{ OR } & \multicolumn{2}{|c|}{$95 \%$ Cl for OR } \\
\hline & & & & Lower & Upper \\
\hline \multicolumn{6}{|c|}{ Step $1(p=0.116)$} \\
\hline \multirow[t]{5}{*}{$r^{2}=0.215$} & Gender & 0.04 & 1.04 & 0.17 & 6.46 \\
\hline & Epirubicin & 1.93 & 6.88 & 0.81 & 58.4 \\
\hline & Diagnosis* & 0.379 & 1.461 & 0.264 & 8.077 \\
\hline & $\mathrm{Age}^{\star \star}$ & -0.726 & 0.484 & 0.056 & 4.202 \\
\hline & Cumulative dose & 0.003 & 1.003 & 1 & 1.007 \\
\hline \multicolumn{6}{|c|}{ Step $2(p=0.062)$} \\
\hline \multirow[t]{4}{*}{$r^{2}=0.215$} & Epirubicin & 1.926 & 6.859 & 0.815 & 57.709 \\
\hline & Diagnosis* & 0.38 & 1.462 & 0.265 & 8.083 \\
\hline & $\mathrm{Age}^{\star *}$ & -0.704 & 0.494 & 0.071 & 3.427 \\
\hline & Cumulative dose & 0.003 & 1.003 & 1 & 1.007 \\
\hline \multicolumn{6}{|c|}{ Step $3(p=0.029)$} \\
\hline \multirow[t]{3}{*}{$r^{2}=0.213$} & Epirubicin & 1.784 & 5.955 & 0.795 & 44.586 \\
\hline & $\mathrm{Age}^{\star \star}$ & -0.752 & 0.471 & 0.069 & 3.237 \\
\hline & Cumulative dose & 0.003 & 1.003 & 1 & 1.007 \\
\hline \multicolumn{6}{|c|}{ Step $4(p=0.013)$} \\
\hline \multirow[t]{2}{*}{$r^{2}=0.203$} & Epirubicin & 1.546 & 4.692 & 0.758 & 29.035 \\
\hline & Cumulative dose & 0.004 & 1.004 & 1.001 & 1.007 \\
\hline
\end{tabular}

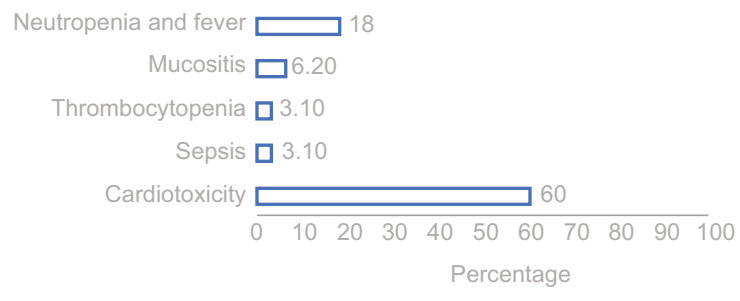

Figure 3. Prevalence of anthracycline-associated complications.

useful to determine the initiation of heart protection treatment..$^{20}$

The main mechanism of anthracycline-induced CTX appears to involve the generation of highly reactive oxygen radicals, which promote lipid peroxidation, which in turn damages the cell membrane. ${ }^{21}$ Anthracycline toxic effects on myocardiocytes lead to left ventricular wall thinning, which increases afterload and decreases contractility, thus resulting in congestive heart failure..$^{22}$ The European guidelines recommend surveillance of patients with high clinical risk, even though risk factors in pediatric patients are not well described. ${ }^{23}$

In clinical practice, follow-up after cancer complete remission is for one year after chemotherapy is concluded, whereby the incidence of this phenomenon could be underestimated, especially in children, with whom contact may be lost.

In the multivariate model, adjustment was made according to the main confounding variables: age, gender, type of tumor and cumulative dose. The sample size limited the number of variables in the model; however, an $\mathrm{OR}=1,004$ was observed for the cumulative dose, which was statistically significant. This has important implications: it appears that it is total dose and not the type of anthracycline that is associated with cardiac complications in children, unlike to what occurs in adults.

We can relate this finding to the fact that hematolymphoid neoplasms were the main risk factor in the bivariate model, since patients with this type of tumors 

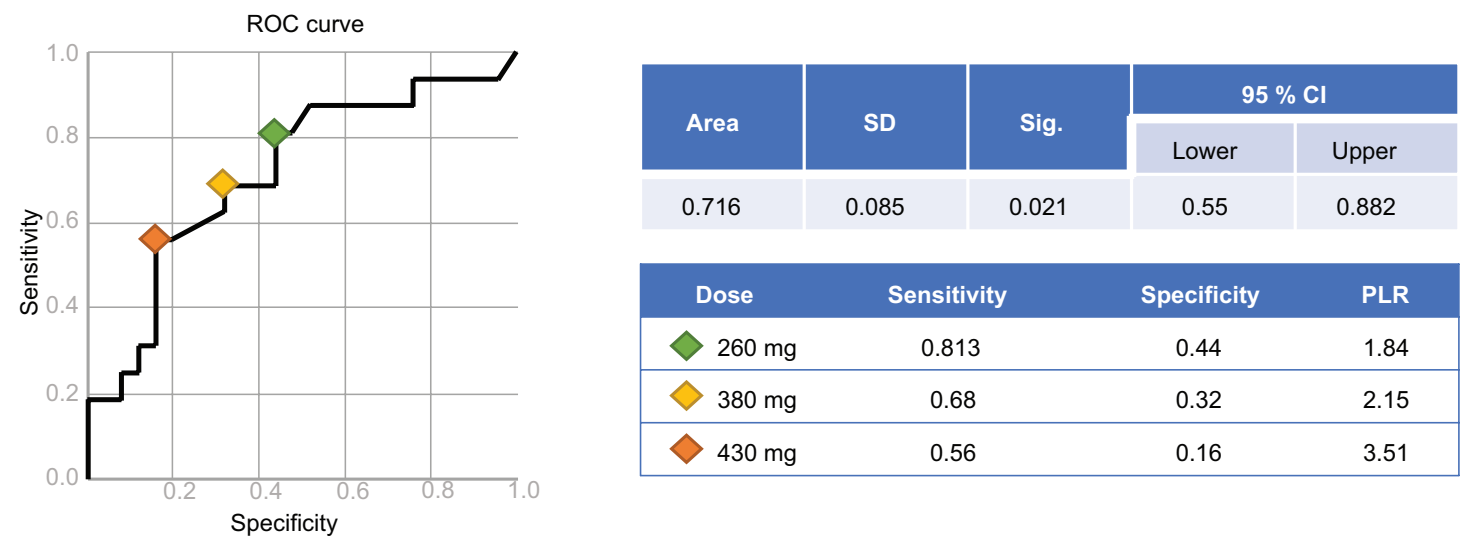

\begin{tabular}{|cccc|}
\hline Dose & Sensitivity & Specificity & PLR \\
\hline $260 \mathrm{mg}$ & 0.813 & 0.44 & 1.84 \\
\hline $380 \mathrm{mg}$ & 0.68 & 0.32 & 2.15 \\
\hline $430 \mathrm{mg}$ & 0.56 & 0.16 & 3.51 \\
\hline
\end{tabular}

Figure 4. ROC curve for the association of cumulative dose and higher likelihood of cardiotoxicity. $P L R=$ positive likelihood ratio. SD $=$ standard deviation. Sig. $=$ significance. .

receive the highest doses of chemotherapy and for a longer period.

The importance of performing these analyses at each country lies in the genetic variants that modify the pharmacology of chemotherapy. ${ }^{24}$

The study herein presented is part of the follow-up of a cohort of pediatric cancer survivors, which has allowed the detection of other adverse events such as hearing loss, ${ }^{25}$ nephrotoxicity, ${ }^{26.27}$ neutropenia and fever, ${ }^{28.29}$ hence the relevance of follow-up studies ${ }^{30}$ and clinical trials that allow adequately addressing the consequences of chemotherapy-associated toxicity. ${ }^{31}$ The cure is not enough, it is necessary to continue with efforts to limit reversible and non-fatal and irreversible adverse events. ${ }^{32,33}$

In this research, we propose that high doses of anthracyclines (regardless of the type) constitute the main risk factor. Consequently, clinicians will be able to offer protective treatments to children who require high doses of anthracyclines, which shall, in theory, lessen one of the most catastrophic complications.

\section{Conclusion}

The main risk factor associated with early cardiotoxicity in Mexican children surviving cancer is a cumulative dose higher than $430 \mathrm{mg}$.

\section{Acknowledgements}

This study is part of \#iniciativaM. We thank the parents of the children, who enabled the performance of the study.

\section{Conflict of interests}

None

\section{Funding}

This research has not received any specific grant from public or commercial sector agencies, or non-profit entities.

\section{Ethical disclosures}

Protection of people and animals. The authors declare that the procedures followed adhered to the ethical standards of the responsible human experimentation committee and were in accordance with the World Medical Association and the Declaration of Helsinki.

Confidentiality of data. The authors declare that they have followed the protocols of their workplace regarding the publication of patient data.

Right to privacy and informed consent. The authors have obtained the informed consent of the patients referred to in the article. This document is in the possession of the corresponding author.

\section{References}

1. Lipshultz SE, Colan SD, Gelber RD, Pérez-Atayde AR, Sallan SE, Sanders SP. Late cardiac effects of doxorubicin therapy for acute lymphoblastic leukemia in childhood. N Engl J Med. 1991;324:808-815.

2. Fajardo-Gutiérrez A, Rendón-Macías ME, Mejía-Aranguré JM. Epidemiología del cáncer en niños mexicanos. Rev Med Inst Mex Seguro Soc. 2011;49:S43-S70.

3. Steinherz LJ, Steinherz PG, Tan CT, Heller G, Murphy ML. Cardiac toxicity 4 to 20 years after completing anthracycline therapy. JAMA. 1991:266:1672-1677.

4. 58a Asamblea Mundial de la Salud: Prevención y Control del Cáncer. Suiza: Organización Mundial de la Salud; 2015. 
5. Instituto Nacional de Estadística y Geografía. Conteo de Población y Vivienda 2010. México: INEGI; 2011.

6. Rivas-Ruiz R, Villasís-Keever M, Miranda-Novales G, Castelán-Martínez OD, Rivas-Contreras S. Outpatient treatment for people with cancer who develop a low-risk febrile neutropaenic event. Cochrane Database Syst Rev. 2019;3:CD009031.

7. Weiss RB. The anthracyclines: will we ever find a better doxorubicin? Semin Oncol. 1992:19:670-686.

8. Mertens AC, Yasui Y, Neglia JP, Potter JD, Nesbit ME Jr, Ruccione K, Smithson WA, Robison LL. Late mortality experience in five-year survivors of childhood and adolescent cancer: The Childhood Cancer Survivor Study. J Clin Oncol. 2001:19:3163-3172.

9. Oeffinger KC, Mertens AC, Sklar CA, Kawashima T, Hudson MM, Meadows AT, et al. Chronic health conditions in adult survivors of childhood cancer. N Engl J Med. 2006;355:1572-1582.

10. Reulen RC, Winter DL, Frobisher C, Lancashire ER, Stiller CA Jenney ME, Skinner R, et al. Long-term cause-specific mortality among survivors of childhood cancer. JAMA. 2010;304:172-179.

11. Steinherz LJ, Steinherz PG, Tan CT, Heller G, Murphy ML. Cardiac toxicity 4 to 20 years after completing anthracycline therapy. JAMA. $1991 ; 266: 1672-1677$

12. Kremer LC, van Dalen EC, Offringa M, Voûte PA. Frequency and risk factors of anthracycline-induced clinical heart failure in children: a systematic review. Ann Oncol. 2002;13:503-512.

13. McEvoy GK, editor. AHFS 2005 Drug Information. EE. UU.: American Society of Health-System Pharmacists; 2005. p. 972-982.

14. Repchinsky C. Compendium of pharmaceuticals and specialties. Canadá: Canadian Pharmacists Association; 2005

15. McGowan JV, Chung R, Maulik A, Piotrowska I, Walker JM, Yellon DM Anthracycline chemotherapy and cardiotoxicity. Cardiovasc Drugs Ther. 2017;31:63-75

16. Pérez-Rodríguez M, Palacios-Cruz L, Rivas-Ruiz R, Talavera JO. Clinical research XXIV. From clinical judgment to ethics in research on humans. Rev Med Inst Mex Seguro Soc. 2014;52:666-672.

17. Vargas-Neri JL, Castelán-Martínez OD, Estrada-Loza MJ, Betanzos-Cabrera Y, Rivas-Ruiz R. Anthracycline-induced cardiotoxicity: report of fatal cases. Rev Med Inst Mex Seguro Soc. 2016;54:404-408.

18. Chow EJ, Leger KJ, Bhatt NS, Mulrooney DA, Ross CJ, Aggarwal S, et al. Pediatric cardio-oncology: epidemiology, screening, prevention, and treatment. Cardiovasc Res. 2019;115:922-934.

19. Doxorubicin Product Monograph. Canadá: Mayne Pharma; 2002.

20. Henriksen PA. Anthracycline cardiotoxicity: an update on mechanisms, monitoring and prevention. Heart. 2018;104:971-977.
21. Gewirtz DA. A critical evaluation of the mechanisms of action proposed for the antitumor effects of the anthracycline antibiotics adriamycin and daunorubicin. Biochem Pharmacol. 1999;57:727-741.

22. Wouters KA, Kremer LC, Miller TL, Herman EH, Lipshultz SE. Protecting against anthracycline-induced myocardial damage: a review of the most promising strategies. Br J Haematol. 2005;131:561-578.

23. Bonadonna G, Monfardini S. Cardiac toxicity of daunorubicin. Lancet. $1969: 1: 837$

24. Zazuli Z, Vijverberg S, Slob E, Liu G, Carleton B, Veltman J, et al. Genetic variations and cisplatin nephrotoxicity: a systematic review. Front Pharmacol. 2018:9:1111.

25. Castelán-Martínez OD, Jiménez-Méndez $R$, Rodríguez-Islas $F$, Fierro-Evans M, Vázquez-Gómez BE, Medina-Sansón A, et al. Hearing loss in Mexican children treated with cisplatin. Int J Pediatr Otorhinolaryngol. 2014;78:1456-1460

26. Jiménez-Triana CA, Castelán-Martínez OD, Rivas-Ruiz $R$, Jiménez-Mén$\operatorname{dez}$ R, Medina A, Clark P, et al. Cisplatin nephrotoxicity and longitudinal growth in children with solid tumors: a retrospective cohort study. Medicine (Baltimore). 2015:94:e1413.

27. Gavrilovici C, Luca A, Antoniu AS, Gallaby K, Starcea M, Miron I, et al. How nephrotoxic is the cancer therapy in children? Farmacia. 2018:66:197-208

28. Castelán-Martínez OD, Rodríguez-Islas F, Vargas-Neri JL, Palomo-Colli MA, López-Aguilar E, Clark P, et al. Risk factors for febrile neutropenia in children with solid tumors treated with cisplatin-based chemotherapy. J Pediatr Hematol Oncol. 2016;38:191-196.

29. Gil-Veloz M, Pacheco-Rosas DO, Solórzano-Santos F, Villasís-Keever MA, Betanzos-Cabrera Y, Miranda-Novales G. Early discharge of pediatric patients with cancer, fever, and neutropenia with low-risk of systemic infection. Bold Med Hosp Infant Mex. 2018;75:352-357.

30. Zhou L, Rupa AP. Categorization and association analysis of risk factors for adverse drug events. EurL J Clin Pharmacol. 2018;74:389404.

31. Pacheco-Rosas DO, Peregrino-Bejarano L, López-Aguilar JE, JuanShum L, Miranda-Novales MG. Piperacillin/tazobactam plus amikacin vs. piperacilin/tazobactam: treatment for children with febrile neutropenia. Rev Med Inst Mex Seguro Soc. 2019;57:65-73.

32. Cortés-Cerda R, Mora-Ríos FG, Insunza-Ramírez A, Mejía-Rohenes LC, Ruiz-Alva SK, Pérez García CK. Benign tumors that cause fractures in children. Acta Ortop Mex. 2018:32:283-286.

33. Ohtani K, Ide T, Hiasa KI, Sakamoto I, Yamashita N, Kubo M, et al. Cardioprotective effect of renin-angiotensin inhibitors and $\beta$-blockers in trastuzumab-related cardiotoxicity. Clin Res Cardiol. 2019;108:1128-1139. 